\title{
O psicólogo com o bisturi na mão: um estudo antropológico da cirurgia plástica*
}

\section{Daniela Feriani $^{* *}$}

O que as cirurgias plásticas podem nos dizer sobre corpos, padrões de beleza, relações de gênero? Normalmente pensadas de forma genérica $e$ associadas à estética $e$ às classes mais favorecidas economicamente, as cirurgias plásticas ganham novos significados e referenciais analíticos na etnografia de Andrea Tochio. Ao olhar para outros contextos, como o de um hospital público, a autora traz novos elementos para se pensar temas já muito discutidos nas ciências sociais, como corporalidade, gênero, beleza, além de permear um campo em ascensão, o da antropologia da saúde.

Resultado da dissertação de mestrado em Antropologia Social na Universidade Estadual de Campinas, o livro oferece uma descrição detalhada das estratégias adotadas pela antropóloga para a realização de uma pesquisa envolvendo entrevistas $e$ conversas informais com pacientes $e$ médicos $e \quad o$ acompanhamento de consultas antes e depois das cirurgias. Vemos com clareza o perfil social dos pacientes, os tipos de operação por eles reivindicados $e$ as razões alegadas para a demanda de intervenção corporal. Compreendemos o modo pelo qual a falta de autoestima pode se transformar numa espécie de "doença" que a plástica pode "curar". A autoestima é uma categoria usada tanto pelos pacientes como pelos médicos, num jogo retórico que envolve constrangimento, dilemas e expectativas

\footnotetext{
* Resenha de TochIO, Andrea. O psicólogo com o bisturi na mão: um estudo antropológico da cirurgia plástica. São Paulo, Annablume, Fapesp, 2012. Recebida para publicação em 13 de março de 2013, aceita em 30 de abril de 2013.

** Doutoranda em Antropologia Social na Universidade Estadual de Campinas. daniferiani@hotmail.com
} 
de ambas as partes. Funciona como uma espécie de arma retórica para aceitação ou recusa da demanda, além de acionar concepções referentes a corpo, gênero e velhice.

O ponto forte de $\mathrm{O}$ psicólogo com o bisturi na mão é ter olhado para um contexto de certa forma negligenciado no imaginário sobre as cirurgias plásticas - o de um hospital público voltado, principalmente, para classes populares -, o que permitiu trazer novos elementos para a compreensão do tema. A especificidade do Hospital de Clínicas da Unicamp, um hospitalescola de atendimento majoritário à população economicamente desfavorecida, traz dilemas para o serviço de cirurgia plástica, pois, devendo, ao menos na teoria, priorizar os procedimentos tidos como reparadores - vistos como mais urgentes e úteis por envolver cuidados referentes à saúde do paciente -, o atendimento é marcado por retóricas, constrangimentos $e$ negociações entre os residentes, que precisam decidir pela aceitação ou recusa da cirurgia, e os pacientes, que desejam ter os pedidos atendidos, ainda que não se encaixem no perfil do hospital. ${ }^{1}$ Esse "jogo sutil", nas palavras da autora, revela não só as estratégias de ambas as partes, mas, principalmente, como essas estratégias se relacionam com concepções sobre corpo, gênero, beleza, saúde e velhice.

A pesquisa de campo no $\mathrm{HC}$ envolveu o acompanhamento de consultas médicas, cirurgias, retornos pós-operatórios, reuniões de discussão de casos entre residentes e médicos e a realização de entrevistas com residentes e pacientes. Foram 73 pacientes entrevistados, sendo 12 homens e 61 mulheres, majoritariamente da classe popular, de diferentes idades (dos 17 aos 77 anos, entre

1 A prioridade do $\mathrm{HC} /$ Unicamp é por cirurgias reparadoras - que envolvem aspectos relacionados à saúde, com sintomas próprios de doenças como dores, tendo como exemplos deformidades causadas por acidentes, queimaduras $e$ casos de ex-obesos que fizeram a cirurgia de redução do estômago. Porém, segundo dados da pesquisa de campo realizada pela autora, de cada 60/80 pacientes por dia, 30 são de estética. Ainda que os residentes defendam a prioridade das cirurgias reparadoras, reconhecem ser importante a realização de cirurgias estéticas como aprendizado, uma vez que, em consultórios particulares, a estética corresponde a 90/95\% dos casos. 
as mulheres, e dos 18 aos 40 anos, entre os homens). Ao recusar explicações genéricas e essencialistas, Tochio se propõe a problematizar o fato de a maioria das pessoas que procura a cirurgia plástica ser mulher, mostrando a diversidade presente nessa categoria ao conectá-la a outros marcadores sociais, como classe e idade, além de também estar interessada nos significados que tais cirurgias têm para os homens.

De uma maneira geral, tanto homens quanto mulheres alegam ser o "aumento da autoestima" o principal motivo para a realização da cirurgia plástica. A preocupação com a aparência, a insatisfação com o corpo, os complexos, os incômodos, as dores físicas e emocionais, o peso do olhar do outro, a inadequação de partes do corpo aos modelos tidos como adequados são questões comuns nas narrativas $e$ as cirurgias aparecem como tentativas de reparar tais desconfortos. Nesse sentido, mesmo uma cirurgia estética, como uma prótese de silicone, por exemplo, não é vista apenas voltada para a beleza e a aparência: é também reparadora, voltada para a saúde, o cuidar de si, o sentir-se bem, sendo a baixa autoestima vista "como uma espécie de "doença" que a cirurgia poderia "curar"” (p.123).

A dissolução das fronteiras entre "estética" e "reparadora" também se faz presente nas falas dos médicos e residentes. Ao afirmar, durante uma palestra, que "o cirurgião plástico é o psicólogo com o bisturi na mão" - daí o título do livro -, Ivo Pitanguy acredita que a cirurgia plástica restaura a correlação entre o psi e o físico do paciente, diluindo a oposição entre mente e corpo. A noção de beleza se expande e se conecta à de bemestar, saúde e felicidade numa tentativa de livrar a cirurgia plástica de um significado meramente ligado à vaidade e à futilidade. Um dos momentos mais interessantes da análise de Tochio é quando mostra como os pacientes e os cirurgiões, conscientes desse discurso sobre a plástica, acionam e manipulam elementos na tentativa de fazer o que desejam. Em outras palavras, há um jogo retórico, marcado por relações de poder e valores morais, no qual ora se dissolve a separação entre estética e reparação, como justificativa, por exemplo, para se fazer a cirurgia; ora se faz uso 
dessa separação para recusar o procedimento. Alguns pacientes se apropriam da retórica médica, o que a autora chamou de "ideologia da reparação", enfatizando as dores físicas, as restrições $e$ os complexos psicológicos - e omitindo outros motivos relacionados à estética - como estratégia de convencimento para a realização da cirurgia desejada. ${ }^{2}$ Por outro lado, os cirurgiões fazem uso da mesma retórica para convencer o paciente de que sua cirurgia não pode ser realizada. Cabe-se perguntar - e a autora o faz - quando se aciona a oposição entre estética $e$ reparação e quando ela é dissolvida.

E é com essa pergunta que a análise sai de um nível mais geral - o da representação - e entra em um mais específico ou etnográfico - o da experiência -, o que permitiu à autora - e a nós, leitores - a percepção do quão heterogêneo é o universo pesquisado. A classificação da cirurgia como estética ou reparadora vem acoplada a uma série de significados $e$ moralidades referentes a gênero, corpo, idade, o que leva a uma tipificação dos próprios pacientes. Os cirurgiões veem como "bons pacientes" aqueles que desejam fazer a cirurgia para si como uma busca autônoma e disciplinada da satisfação pessoal, o que a autora chamou, utilizando Edmonds (2002), de "ethos puritano". Nesses casos, uma cirurgia que poderia ser considerada estética tende a se transformar em uma cirurgia reparadora, sendo, portanto, realizada. Já os "maus pacientes" são aqueles que desejam realizar o procedimento cirúrgico para agradar outrem (arrumar namorado, reconquistar o marido, conseguir emprego), o que caracterizaria um "ethos hedonista", sendo as cirurgias vistas como estéticas e, assim, recusadas. Para os médicos, tais pacientes são vistos como "problema", pois nunca ficarão

\footnotetext{
2 Tochio conta o caso de uma mulher que queria reduzir as mamas, alegando ser em razão das fortes dores na coluna. Quando o residente sai da sala de consulta para discutir o caso com o médico, ficando apenas a paciente e a pesquisadora, aquela admite que o motivo é estético, ou seja, queria fazer a cirurgia para ficar mais bonita e reconquistar o marido. A paciente pede para a pesquisadora não comentar sobre o verdadeiro motivo com o residente, temendo que a cirurgia fosse negada.
} 
satisfeitos com o resultado da cirurgia, já que as expectativas e os motivos que os levam a desejá-la ultrapassam-na e não está ao alcance dos cirurgiões solucioná-los.

Além desses dois tipos de ethos, as decisões dos residentes de fazer ou não a cirurgia também se devem às concepções sociais sobre corpo, gênero e idade. Para pensar a relação entre corpo e gênero, Tochio se detêm em uma parte do corpo que ganha conteúdos diversos para homens e mulheres - as mamas. Em revistas especializadas sobre o tema e em convênios particulares, a redução de mamas é tida como estética, tanto em homens quanto em mulheres. Porém, no cotidiano do hospital estudado, enquanto a cirurgia nas mulheres é classificada como estética, a cirurgia nos homens é vista como reparadora. Aliás, a autora mostra que, para os 12 homens pesquisados, apenas 2 cirurgias foram consideradas estéticas, mesmo sendo a ginecomastia (redução de mamas) e a rinoplastia (cirurgia plástica no nariz) as mais procuradas entre eles. ${ }^{3}$ Como a autora analisa, a mama nos homens é considerada uma patologia, revelando o que Corrêa (2004) chamou de "ideologia do dimorfismo sexual". As cirurgias plásticas são, assim, tentativas de fixar, moldar e até mesmo produzir diferenças entre corpo feminino e corpo masculino, diferenças essas tidas como naturais, cortando e costurando as partes que fogem dessa dicotomia para que se encaixem nos padrões corporais e sexuais atribuídos a homens e mulheres.

Já na relação corpo e velhice,

a cirurgia é uma tentativa de fugir das marcas do tempo, desnaturalizando processos tidos como naturais. $\mathrm{O}$ envelhecimento é visto como um processo de perda de saúde e da beleza que é associada com a juventude e o bem-estar (p.159).

${ }^{3}$ Entre as mulheres, as cirurgias mais procuradas foram a mamoplastia (redução das mamas) e a abdominoplastia (remoção do excesso de pele e de gordura da parte inferior do abdômen), sendo a maioria considerada estética. 
Se as mais jovens concentram seus esforços nas mamas, as mais velhas buscam principalmente intervir na face, o que nos mostra o processo de fragmentação do corpo e da própria velhice, fragmentação essa muito bem utilizada pelos médicos na tipificação das cirurgias, cada uma tendo o nome relacionado à parte do corpo que sofrerá o procedimento. Recorrendo a Debert (2004), Tochio analisa como a juventude se torna um valor a se desejar e buscar, independentemente da idade, enquanto a velhice, também independentemente da idade, é tida como uma atitude de negligência com o corpo, "uma espécie de "doença autoinfligida", como são vistos hoje o fumo, as bebidas alcoólicas e as drogas" (p.161).

Apesar de compartilhar de uma bibliografia (principalmente Csordas, 1996) que vê o corpo como algo plástico, moldável, flexível, como agente e experienciador, sendo as cirurgias plásticas projetos corporais constantes e quase intermináveis ${ }^{4}$, Tochio nos traz outra perspectiva: é muito mais a normalização dos corpos do que a plasticidade deles que está em jogo nesses procedimentos. Nas palavras de Debert, no prefácio desse livro,

\begin{abstract}
Aprendemos que não se pode pensar na cirurgia plástica como algo que amplia a plasticidade do corpo, idéia que é a pedra de toque dos estudos sobre o tema. É antes preciso pensar nos limites que essa indústria impõe às possibilidades do corpo e nesse sentido esse livro traz um novo prisma à reflexão sobre as formas de encarceramento da diversidade corporal. As operações realizadas apontam as severas limitações que são impostas sobre o corpo e é a aversão ao diferente que organiza as reformatações corporais empreendidas (p.16).
\end{abstract}

\footnotetext{
4 A autora mostra que, por se tratar de um serviço público e gratuito, a cirurgia é vista quase como um prêmio, sendo sua realização mais importante do que a parte do corpo que sofrerá a intervenção. Além disso, há muitos casos de pacientes que, depois de uma cirurgia, retornam para fazer outra em nova parte do corpo, e de pacientes que, numa mesma consulta, pedem a realização de mais de uma cirurgia.
} 
$\mathrm{Na}$ busca por corpos adequados às concepções vigentes sobre gênero, beleza e velhice, a estética vai sendo ressignificada $e$ acoplada a outras dimensões, tais como moralidade, saúde, felicidade e bem-estar. Tochio argumenta que há um imperativo moral que nos obriga ao cuidado de si e ao aumento da autoestima. A aparência deixa de ser uma mera questão de vaidade e futilidade para se tornar uma questão de saúde $e$ moralidade, sendo o corpo gordo e o corpo velho vistos como desleixados, indisciplinados, falhos, em um processo de responsabilização cada vez maior do indivíduo pelas próprias saúde e felicidade. Nas palavras da autora, "a estética aqui vem acoplada à ética envolvida na luta para sentir-se bonita, com boa aparência, como parte da obrigação moral de sentir-se bem $e$ portar-se de uma determinada maneira no mundo" (p.119). A cirurgia plástica acaba sendo um modo de revelar o eu verdadeiro, antes escondido sob um corpo inadequado, ou, então, fabricá-lo através da transformação da própria identidade (com diz uma paciente, "tornei-me outra pessoa").

Ainda que se deva levar em conta que se trata de um livro fruto de uma pesquisa de mestrado $e$, portanto, com todas as limitações de tempo, espaço e objeto que isso implica, a etnografia ganharia ainda mais fôlego analítico se a bibliografia tivesse sido mais ampla $e$ mais generosa aos estudos sobre gênero $e$ sexualidade, principalmente. Se, por um lado, uma discussão bibliográfica mais enxuta trouxe dinamismo e fluidez ao texto, com capítulos breves e linguagem leve, deixou de lado autores $e$ estudos importantes para a compreensão do tema. Destacaria as contribuições de Foucault sobre a relação entre saber e poder na sexualidade e no corpo através do discurso médico, de Laqueur sobre a desnaturalização dos sexos e a categoria "dimorfismo sexual", de Anne Fausto-Sterling sobre a "mitologia do normal" que formata corpos, sexualidades e relações de gênero, entre outras que poderiam ter tornado a análise mais densa.

Um dos méritos do livro, além do já mencionado olhar para um contexto normalmente negligenciado nos estudos sobre cirurgia plástica e trazer, com isso, uma nova perspectiva para o 
tema, é ter levado em conta o ponto de vista dos pacientes através da análise de suas narrativas, o que ainda é pouco usual nos estudos sobre saúde, doença e medicina. Fazer essa análise permitiu perceber as possibilidades de manobras, conflitos $e$ negociações de valores pelos sujeitos envolvidos, além de relativizar os discursos oficiais e hegemônicos.

Em um país que ocupa a segunda posição no ranking mundial de cirurgias plásticas, $O$ psicólogo com o bisturi na mão é um convite para a reflexão e a sensibilidade que o tema nos exige, mostrando como corpos se posicionam diferentemente para homens e mulheres, pobres e ricos, jovens e velhos.

\section{Referências bibliográficas}

CORREA, Mariza. Fantasias corporais. In: PISCITELli, GREGORI \& CARRARA (orgs). Sexualidade e saberes: convenções e fronteiras. Rio de Janeiro, Garamond, 2004, pp.173-182.

CSORDAS, T.J. Introduction: the body as representation and being in the world. In: Embodiment and Experience: The existencial ground of culture and self. New York, Cambrigde Univesity Press, 1996, pp.1-24.

DEBERT, Guita Grin. A cultura adulta e juventude como valor. Paper apresentado no ST13 Imagens da Modernidade: Mídia, consumo e relações de poder, na XXVIII Reunião da Associação Brasileira de Pós-Graduação e Pesquisa em Ciências Sociais, realizada em Caxambu (MG), de 26 a 30 de outubro de 2004.

EDMONDS, A. No universo da beleza: notas de campo sobre cirurgia plástica no Rio de Janeiro. In: Goldemberg, Miriam (org.). Nu e vestido, R.J, Record, 2002, pp.189-261. 